\title{
ALTERNATIVE TREATMENT STRATEGY FOR DIFFERENT STREAMS OF TANNERY WASTEWATER
}

\author{
Lucyna Przywara ${ }^{1}$ \\ 1 Faculty of Materials, Civil and Environmental Engineering University of Bielsko-Biala, Willowa St. 2, 43-300, \\ Bielsko-Biala, Poland, e- mail: I.przywara@ath.bielsko.pl
}

Received: 2017.04.30

Accepted: 2017.05.31

Published: 2017.07.01

\begin{abstract}
This article discusses the results of laboratory tests aimed to determine the effectiveness of tannery wastewater treatment in the process of enhanced oxidation using Fenton reagent. The general sewage from the tannery located in Mazowieckie Province was used for the research. The process was carried out using two doses of iron of 0.45 $\mathrm{g} \mathrm{Fe}^{2+} / \mathrm{dm}^{3}$ and $0.56 \mathrm{~g} \mathrm{Fe}^{2+} / \mathrm{dm}^{3}$, and $\mathrm{H}_{2} \mathrm{O}_{2}$ from $2.21 \mathrm{~g} / \mathrm{dm}^{3}$ to $4.08 \mathrm{~g} / \mathrm{dm}^{3}$. All the tests were performed for a constant optimum $\mathrm{pH}$ of 3.0. Wastewater was characterized by basic physico-chemical indicators ( $\mathrm{pH}$, conductivity, $\mathrm{COD}$, chromium, ammonium nitrogen). The efficiency of the process was determined mainly on the basis of changes in the organic pollutants identified as COD. The efficacy of the Fenton process for different doses of $\mathrm{Fe}^{2+}$ and $\mathrm{Fe}^{2+} / \mathrm{H}_{2} \mathrm{O}_{2}$ ratio of 1: 5, 1: 6 and 1: 7 was from 69 to $80 \% \mathrm{COD}$ reduction in relation to raw sewage. Another aspect of the study was determining the possibility of removing sulphides from the wastewater by catalytic oxygenation with oxygen from air in the presence of manganese. In this case, the wastewater produced during leather manufacture in tanneries located in the southern part of Poland was examined. The subject of the study described in the paper was to determine the optimum manganese dose and oxidation time to simultaneously remove the sulphides and organic pollutants expressed as COD. The change in pollutant content in the wastewater over time indicates that the reduction of parameters takes place within one hour after the addition of manganese. Using the process of catalytic oxidation with $0.1 \mathrm{~g} / \mathrm{dm}^{3}$ to $0.6 \mathrm{~g} / \mathrm{dm}^{3}$ manganese and a reaction time of $1,3,24 \mathrm{~h}$, the sulphides were removed in the range of 50 to $99 \%$ and organic compounds in 12 to $65 \%$.
\end{abstract}

Keywords: tannery wastewater, Fenton's reagent, catalytic oxidation, COD, sulphide

\section{INTRODUCTION}

Leather tanning is the process of transforming skins into stable and imputrescible products. The technique of skin tanning is a complex process that consists of multiple processes and technological operations, including: beamhouse operation, tanning proper, retanning and finishing (Lofrano et al. 2013, Cooman et al. 2003).

Beamhouse includes the following processes: soaking, liming, chemical or mechanical removal of hair, degreasing and pickling. Then the raw materials are tanned. Two methods are adopted for tanning of raw hide, vegetable tanning and chrome tanning (Durai et al. 2011).
Retanning and wet finishing processes give the tanned hide special or desired characteristics. Finishing includes all operations performed on the hide after fat liquoring and includes the enhancement of colour resistance to stains and abrasions, smoothing and stretching the skin, drying, conditioning, staking, dry milling, buffing and plating (Lofrano et al. 2013).

Tannery wastewater is characterized by high contents of organic compounds which can leach from the skin (such as fats and proteins), inorganic compounds including chromium, sulphide, nitrogen (Chowdhury et al. 2013). Organic pollutants (proteic and lipidic components) originate from skins (it is calculated that raw skin has los- 
es $30 \%$ of organic material during the working cycle) or they are introduced during processes (Lofrano et al. 2013). Acids, bases and salts of chromium (III), sulphide, and many other compounds which are used in the process of raw skin conversion into leather remain in the wastewater.

With traditional methods of tannery wastewater neutralization such as physicochemical processes [Song et al. 2004, Kowalik et al. 2009, Chowdhury et al. 2013], chemical processes [Naumczyk et al. 2005, Ramashraya et al. 2011] or biological processes [Kotulska et al. 2006, Durai et al. 2011, Mendrycka et al. 2012], it is becoming increasingly difficult to treat the wastewater to the level of current requirements for the quality of waste water discharged into the environment. For this reason, well-known wastewater treatment methods are constantly improved or new solutions are sought. In many cases, to achieve the required end results, several methods [Song 2001, Mandal et al. 2010, Ayoub et al. 2011] or treatment of separated waste streams need to be used. This allows for the pre-treatment of highly concentrated waste water, which especially applies to wastewater containing sulphides, chromium or organic compounds. It is often easier and more effective to treat higher-concentration wastewater.

An alternative to conventional tannery wastewater treatment methods can be Advanced Oxidation Processes, including Fenton's reaction [Mandal et al. 2010], which utilize the high oxidation potential of generated hydroxyl radicals at $2.8 \mathrm{~V}$ [Schrank et al. 2005, Ramasharya et al. 2011, Abdel-Aal et al. 2015].

The effectiveness of pollutants removal from the wastewater with these methods depends mainly on the type and amount of organic compounds that undergo oxidation and on the presence of organic and mineral compounds that stimulate or inhibit the formation of hydroxyl radicals $\mathrm{OH}^{*}$, as well as doses of reactants, $\mathrm{Fe}^{2+}$ / $\mathrm{H}_{2} \mathrm{O}_{2}$ (iron ions) ratio in the case of the Fenton's process [Cesaro et al. 2013]. Oxidation of the compounds in this method is most effective in the $\mathrm{pH}$ range of 2 to 4 , because in this range catalytic decomposition of $\mathrm{H}_{2} \mathrm{O}_{2}$ results in the formation of hydroxyl radicals $\mathrm{OH}^{*}$ [Neyens and Baeyens 2003]. The mechanism of the reaction involves many steps and these are mainly radical reactions [Barbusiński 2009].

The main discrepancies in the results are related to the type of tannery wastewater used in the study but also to the dosage of the reac- tants, i.e. iron sulphate, used, often expressed as $\mathrm{Fe}^{2+}$ and hydrogen peroxide used to remove organic compounds.

The research discussed in the paper by AbdelAal et al. [2015] indicate that organic compounds designated as COD are removed in $90.1 \%$ when the process is carried out using $0.8 \mathrm{~g}$ of $\mathrm{Fe} / \mathrm{dm}^{3}$ and $30 \mathrm{~g}$ of $\mathrm{H}_{2} \mathrm{O}_{2} / \mathrm{dm}^{3}$. The authors of the paper by Mandal et al. [2010] report that COD removal efficiency even at the highest dose of $\mathrm{FeSO}_{4}(6 \mathrm{~g} /$ $\mathrm{dm}^{3}$ ) and $111 \mathrm{~g} / \mathrm{dm}^{3}$ of $\mathrm{H}_{2} \mathrm{O}_{2}$ did not exceed $46 \%$. Removal of COD during the same process with the same dose of $\mathrm{FeSO}_{4}$ but $\mathrm{H}_{2} \mathrm{O}_{2}$ dose increased to $266.6 \mathrm{~g} / \mathrm{dm}^{3}$ was $68 \%$.

The application of the coagulation process prior to the enhanced oxidation with Fenton reagent contributes to increasing the organic compounds removal efficiency, as outlined by Schrank et al. [2005] and Naumczyk et al. [2005]

Fenton oxidation is one of the most effective methods for removing pollutants from sewage. Moreover, the advantage of Fenton's reaction is that in addition to oxidation processes coagulation of pollutants occurs [Xing et al. 2006].

Another very important issue in the tanning industry is the removal of sulphides generated during processes called liming and dehairing from wastewater. In these processes, sodium sulphide or sodium hydrosulphide is used to treat the hides. The presence of sulphides in sewage is a hazard because of the possibility of the hydrogen sulphide emission, whose toxic properties are determined already at the content in air above $1 \mathrm{ppm}$ [Kociołek et al. 2012a]. One of the most efficient methods for removing sulphides is oxidation. It involves the oxidation of sulphides into products of lesser nuisance, mainly to elemental sulphur and sulphates (VI), but also to thiosulphates and sulphates (IV) [Kociołek et al. 2012b]. Classical oxidants such as oxygen, ozone, hydrogen peroxide and chlorine and its compounds are used to oxidize sulphides. Chemistry of oxidation processes and the type of products produced are complex and depends mainly on the molar ratio of the reactants or the $\mathrm{pH}$ of the environment. It is also possible to remove sulphides in the process of catalytic oxidation with oxygen from the air in the presence of manganese, because in the sewage separated after the purification process a sulphide content of 2 to $10 \mathrm{mg} \mathrm{S} \mathrm{S}^{2-} / \mathrm{dm}^{3}$ is obtained, for a recommended amount of manganese from 100 to $200 \mathrm{mg} / \mathrm{dm}^{3}$ [BAT, 2013]. Using this method for general sewage can reduce the con- 
centration of sulphides 3.5 times and additionally reduce the content of organic compounds by only 6-9\% [Rameshraja et al. 2011].

The purpose of the research was to determine the possibility of purifying separated sewage streams generated during the processing of hides. Determining the optimal dose of $\mathrm{Fe}^{2+}$ and $\mathrm{H}_{2} \mathrm{O}_{2}$, the $\mathrm{Fe}^{2+}$ to $\mathrm{H}_{2} \mathrm{O}_{2}$ ratio used in the Fenton method for the resulting purification efficiency was carried out for general sewage from tannery where hide pre-treatment processes were not carried out. On the other hand, catalytic oxidation with manganese sulphate was carried out on wastewater containing significant amounts of sulphides derived from liming and dehairing processes. The purpose of the study described was to determine the optimum manganese dose and oxidation time to simultaneously remove the sulphides and organic pollutants expressed as COD.

\section{MATERIALS AND METHODS}

\section{Fenton's oxidation process}

The research was carried out on real sewage from the tannery located in Mazowieckie Province. The process of enhanced oxidation with Fenton reagent was carried out in $2 \mathrm{dm}^{3}$ glass vessels using $\mathrm{FeSO}_{4} \times 7 \mathrm{H}_{2} \mathrm{O}$ and $\mathrm{H}_{2} \mathrm{O}_{2}$ reactants dosed into tannery wastewater in the form of $1 \mathrm{~m}$ $\mathrm{FeSO}_{4} \times 7 \mathrm{H}_{2} \mathrm{O} / \mathrm{dm}^{3}$ and $10 \mathrm{mH}_{2} \mathrm{O}_{2} / \mathrm{dm}^{3}$ solutions. The study was conducted for an optimum $\mathrm{pH}$ value of 3 . Such values were also presented as optimal in the works of Cesaro et al. [2013], Lofrano et al. [2013] and Abdel-Aal et al. [2015]. For studies conducted by Przywara [2017] for a $\mathrm{pH}$ of 3 , the removal efficiency of organic compounds was increased from 75 to $81 \%$. Hydrochloric acid at a concentration of $1 \mathrm{~m} / \mathrm{dm}^{3}$ was used to adjust the $\mathrm{pH}$ of the wastewater.

The study was conducted according to the following variants:

- variant 1: reactants introduced at $0.45 \mathrm{~g}$ of Fe/ $\mathrm{dm}^{3}$ and $\mathrm{H}_{2} \mathrm{O}_{2}$ with a $\mathrm{Fe}^{2+} / \mathrm{H}_{2} \mathrm{O}_{2}$ ratio of 1:5, $1: 6$ and $1: 7$,

- variant 2: reactants in the amount of $0.56 \mathrm{~g}$ $\mathrm{Fe}^{2+} / \mathrm{dm}^{3}$ and $\mathrm{H}_{2} \mathrm{O}_{2}$ were introduced, maintaining a 1:5, 1:6, 1:7 ratio.

For rapid distribution of the reactants, rapid stirring was carried out for $5 \mathrm{~min}$ followed by slow stirring for $30 \mathrm{~min}$. For another $30 \mathrm{~min}$. waste samples were subjected to a sedimentation process. After $30 \mathrm{~min}$. of sedimentation samples were taken for analysis from supernatant liquid. The effectiveness of physicochemical processes of tannery wastewater treatment was determined mainly on the basis of changes in the value of organic pollutants i.e. chemical oxygen demand (COD). All physicochemical determinations were made according to the methodology outlined in APHA [2005].

\section{Catalytic oxidation}

The study used the beamhouse wastewater generated during the production of leather from animal hides in tanneries located in the southern part of the Poland. Samples were taken in triplicate. All experiments were performed in three independent series at room temperature.

The testing was carried out in glass vessels with a volume of $2 \mathrm{~L}$ with the use of sulphate (VI) manganese (II). Sulphate (VI) manganese (II) hydrate $\left(\mathrm{MnSO}_{4} \cdot \mathrm{H}_{2} \mathrm{O}\right)$ used as source of analyticalgrade Mn (II) purchased from Merc. Different doses of manganese (II) ranging from $100 \mathrm{mg} / \mathrm{L}$ to $600 \mathrm{mg} / \mathrm{L}$ in the form of manganese (II) sulphate (VI) hydrate $\left(\mathrm{MnSO}_{4} \cdot \mathrm{H} 2 \mathrm{O}\right)$, at increments of $100 \mathrm{mg} / \mathrm{L}$, were used to optimize the processes.

The physical and chemical parameters including $\mathrm{pH}$, electrical conductivity (EC), chemical oxygen demand (COD) and concentrations of sulphide $\left(\mathrm{S}^{2-}\right)$ of untreated and treated sample were measured.

The experiments proceeded with rapid mixing of wastewater sample at $100 \mathrm{rpm}$ for $5 \mathrm{~min}$, followed by slow mixing at $50 \mathrm{rpm}$ for $60 \mathrm{~min}$, $180 \mathrm{~min}$ and $24 \mathrm{~h}$ and simultaneous aeration. After $60 \mathrm{~min}$ of settling, the supernatant was withdrawn for $\mathrm{pH}$, sulphide and COD was determined. The analysis of sulphides $\left(\mathrm{S}^{2-}\right)$, chemical oxygen demand (COD) was carried out according to the standard APHA protocol (2005). Samples for measurements of COD, $\mathrm{S}^{2-}$ were filtered through a $0.45 \mu \mathrm{m}$ membrane (Advantec GC 50) prior to analysis.

The optimization of process of sulphides removal depends on the type reagent, its dose, and time (Abdel-Aal et al. 2015, Lofrano et al. 2010, Lofrano et al. 2013). Finally the optimization of process duration was determined by analysing the removal efficiencies for each parameter after 1,3 and $24 \mathrm{~h}$. 


\section{RESEARCH RESULTS AND DISCUSSION}

\section{Fenton's oxidation process}

The research was carried out on real wastewater from tannery, where the technological process starts with the processing of semi-finished product, i.e. so-called "wet-blue" hide. Thus, in the process of hides tanning there are no processes, such as liming and dehairing, in which sulphur compounds, i.e. sulphides, are used in processing. On the other hand, in the technological operations, organic and inorganic acids, alkaline salts, tanning agents and fungicides are used to obtain better-performing hides. Tannery wastewater include, among others. solubles, suspensions, residues of tanning compounds, organic substances designated as COD or BOD. The characteristics of tanning wastewater used in the studies are presented in Table 1.

The tannery wastewater used for the study was characterized by a reaction of approx. 4, conductivity in the range of 4100 to $5300 \mu \mathrm{S} / \mathrm{cm}$. COD values ranged from 2500 to $5620 \mathrm{mg} \mathrm{O}_{2} /$ $\mathrm{dm}^{3}$, and chromium concentrations from 21 to 47

Table 1. Physicochemical characteristics of the tanning industry wastewater

\begin{tabular}{|l|c|c|}
\hline \multicolumn{1}{|c|}{ Parameter } & Unit & Range of values \\
\hline $\mathrm{pH}$ & - & $3.90-4.50$ \\
\hline Conductivity & $\mu \mathrm{S} / \mathrm{cm}$ & $4100-5300$ \\
\hline $\mathrm{COD}$ & $\mathrm{mg} \mathrm{O} / \mathrm{dm}^{3}$ & $2500-5620$ \\
\hline Chromium & $\mathrm{mg} \mathrm{Cr} / \mathrm{dm}^{3}$ & $21.00-47.00$ \\
\hline $\begin{array}{l}\text { Ammonium } \\
\text { nitrogen }\end{array}$ & ${\mathrm{mg} \mathrm{N}-\mathrm{NH}_{4} / \mathrm{dm}^{3}}^{3}$ & $24.00-65.00$ \\
\hline
\end{tabular}

$\mathrm{mg} \mathrm{Cr} / \mathrm{dm}^{3}$, ammonium nitrogen from 24 to $65 \mathrm{mg}$ $\mathrm{N}-\mathrm{NH}_{4} / \mathrm{dm}^{3}$. The COD values obtained were close to the values reported by Cooman et al. [2003], Naumczyk et al. [2005], Kotulska et al. [2006], Mandal et al. [2010] and Chowdhury et al. [2013].

In the first variant the study was conducted for a dose of $\mathrm{Fe}^{2+}$ an amount of $0.45 \mathrm{~g} / \mathrm{dm}^{3}$. Hydrogen peroxide was added in an amount of 2.21 $\mathrm{g} / \mathrm{dm}^{3}, 2.72 \mathrm{~g} / \mathrm{dm}^{3}$ and $3.23 \mathrm{~g} / \mathrm{dm}^{3}$ to assure the a $\mathrm{Fe}^{2+} / \mathrm{H}_{2} \mathrm{O}_{2}$ ratio of $1: 5,1: 6$ and $1: 7$, respectively. The efficacy of the Fenton process as measured by the COD reduction for these doses was $69 \%$, $72 \%$ and $75 \%$, respectively (Fig. 1).

Based on the studies conducted in this variant, it was found that an increased dose of hydrogen peroxide guarantees better efficiency in the treatment of tannery wastewater, which corresponds to the results reported by Naumczyk et al. [2005].

By introducing reactants in an amount of 0.56 $\mathrm{g}$ of $\mathrm{Fe}^{2+} / \mathrm{dm}^{3}$ and $\mathrm{H}_{2} \mathrm{O}_{2}$ maintaining the $\mathrm{Fe}^{2+} / \mathrm{H}_{2} \mathrm{O}_{2}$ ratio of 1: 5, 1: $61: 7$ in the second variant of the study, the organic compounds expressed as COD were removed in 72 to $80 \%$, as presented in Figure 2 .

The maximum COD removal value of $80 \%$ was obtained for a sample with the following amounts of reactants: $0.56 \mathrm{~g} \mathrm{Fe}^{2+} / \mathrm{dm}^{3}$ and 4.08 $\mathrm{g} \mathrm{H}_{2} \mathrm{O}_{2} / \mathrm{dm}^{3}$. It was found that the increase in the efficiency of removal of organic compounds designated as COD increases with the increase in the amount of reactants added. However, it should be noted that $75 \%$ efficiency was obtained not only for the $\mathrm{Fe}^{2+}$ dose of $0.56 \mathrm{~g} / \mathrm{dm}^{3}$ and the $\mathrm{Fe}^{2+}$ / $\mathrm{H}_{2} \mathrm{O}_{2}$ ratio of 1: 6 , but also for the first variant of the study with $0.45 \mathrm{~g}$ of $\mathrm{Fe}^{2+} / \mathrm{dm}^{3}$ and the $\mathrm{Fe}^{2+} /$ $\mathrm{H}_{2} \mathrm{O}_{2}$ ratio of 1: 7. A similar situation occurred in studies using $\mathrm{Fe}^{2+}$ in the amount of $0.45 \mathrm{~g} / 1$

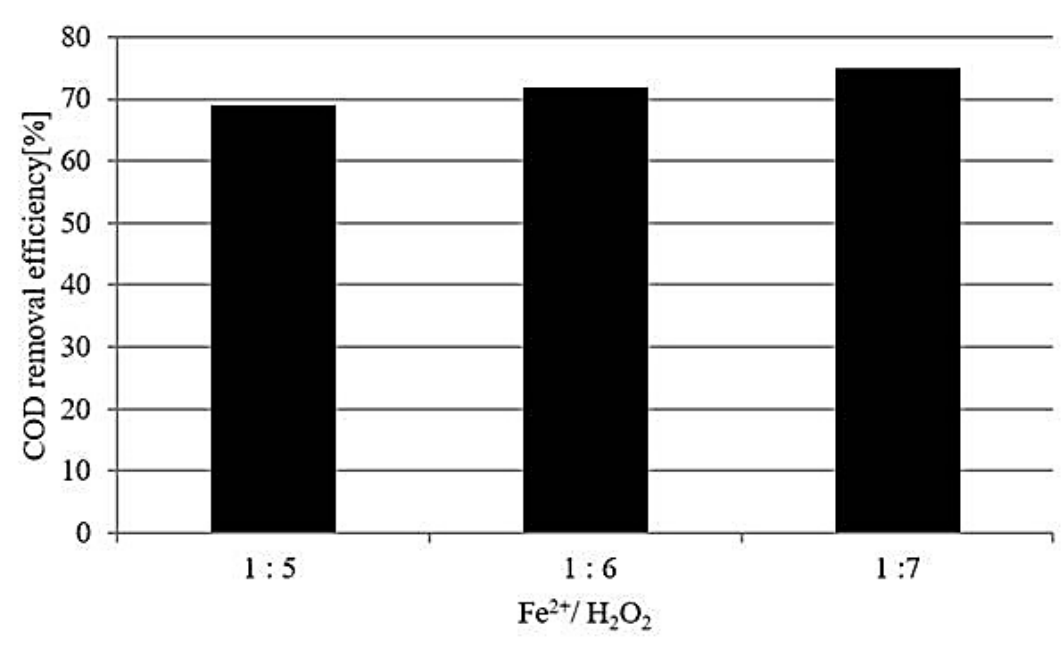

Figure 1. The effect of $\mathrm{Fe}^{2+} / \mathrm{H}_{2} \mathrm{O}_{2}$ ratio on COD removal for $\mathrm{Fe}^{2+}$ dose of $0.45 \mathrm{~g} / \mathrm{dm}^{3}$ 


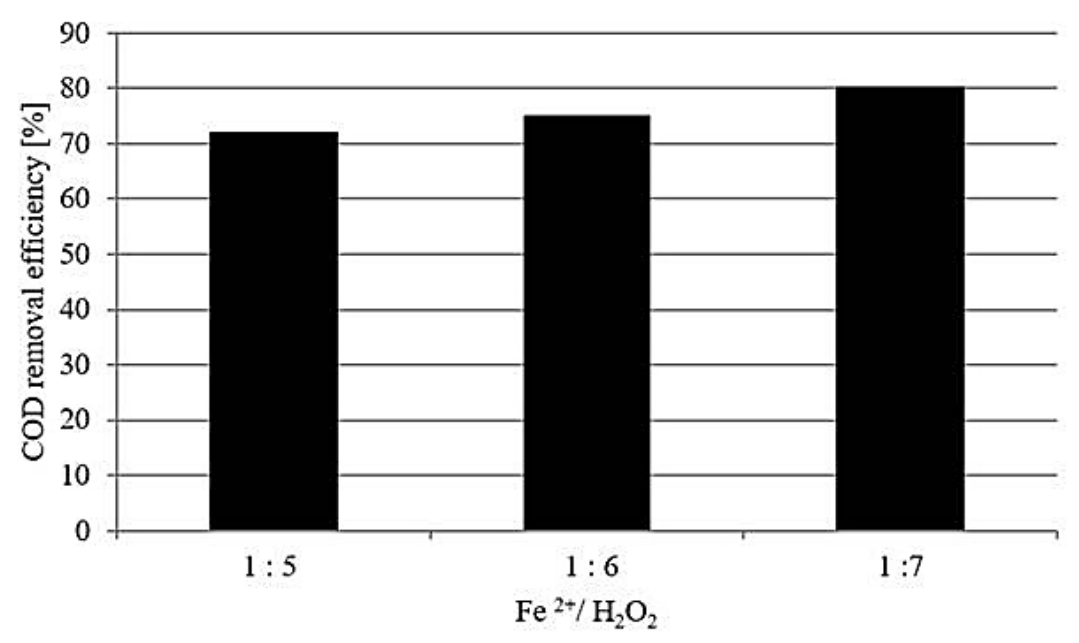

Figure 2. The effect of $\mathrm{Fe}^{2+} / \mathrm{H}_{2} \mathrm{O}_{2}$ ratio on COD removal for $\mathrm{Fe}^{2+}$ dose of $0.56 \mathrm{~g} / \mathrm{dm}^{3}$

and $0.56 \mathrm{~g} / \mathrm{l}$ and $\mathrm{Fe}^{2+} / \mathrm{H}_{2} \mathrm{O}_{2}$ ratio of 1: 6 and 1: 5, respectively. For both cases a COD reduction of $72 \%$ was obtained.

Naumczyk et al. [2005] investigated the Fenton process for tannery wastewater with an initial COD value of 2720 and $2417 \mathrm{mg}$ of $\mathrm{O}_{2} / \mathrm{dm}^{3}$. For significantly higher doses of $\mathrm{Fe}^{2+}$ reactants at a level of $1 \mathrm{~g} \mathrm{Fe}^{2+} / \mathrm{dm}^{3}$, almost twice as much as those described in the present paper, and $4 \mathrm{~g} /$ $\mathrm{dm}^{3}$ of $\mathrm{H}_{2} \mathrm{O}_{2}$, only $54 \%$ of COD reduction was obtained. Similarly, Mandal et al. [2010] have shown that in the treatment of tannery wastewater using Fenton's reagent, only partial removal of maximum $68 \%$ of COD can be obtained using 6 $\mathrm{g} \mathrm{Fe}^{2+} / \mathrm{dm}^{3}$ and $266 \mathrm{~g} / \mathrm{dm}^{3}$ of $\mathrm{H}_{2} \mathrm{O}_{2}$. Schrank et al. [2004], on the other hand, achieved a significantly better oxidation efficiency of organic compounds expressed as COD at a level of $90 \%$.

\section{Catalytic oxidation}

The beamhouse wastewater is characterized by an alkaline $\mathrm{pH}$ between $8.60-9.42$, resulting from the chemicals used in leather processing, such as lime. Wastewater with similar $\mathrm{pH}$ characteristics was found by Lofrano et al. (2013). Untreated wastewater also contained high concentration of organic matter, measured as COD, and high sulphide content as well. The value of COD varies in a wide range $(6320 \div 14000 \mathrm{mg} / \mathrm{L})$ and sulphide concentrations were in the range of $55.4-59.6 \mathrm{mg} / \mathrm{L}$. Sodium sulphide and sodium hydrosulphide are normally used during limingunhairing operation. Both COD and sulphide concentration values of tannery correspond with the results presented by Cooman et al. (2003), Lofrano et al. $(2010,2013)$.
The effect of manganese (II) sulphate (VI) dose on the removal efficiency of sulphide, are shown in Figure 3. The graphs show a common trend, where the removal percentage (\%) of sulphide is initially increased with the increase of the dose until the effectiveness reaches the maximum and then is decreased as the dose increases. The maximum sulphide removal percentage (\%) was obtained for the $500 \mathrm{mg} / \mathrm{L}$ dose of manganese (II).

The highest removal efficiencies for different time of reactions achieved were $80 \%$ (1h), $84 \%$ (3h), 99\% (24 h). After the addition of manganese (II) at the concentration of $400 \mathrm{mg} / \mathrm{L}$ the sulphide concentration decreased by $60 \%, 80 \%$ and $99 \%$ for time reaction $1 \mathrm{~h}, 3 \mathrm{~h}, 24 \mathrm{~h}$ respectively.

Another advantage of using catalytic oxygenation with manganese is the removal of organic substances, which are important pollutants in wastewater too. After the addition of the manganese (II) at a concentration of $100 \mathrm{mg} / \mathrm{L}$, the COD decrease by 12,18 and $21 \%$ for $1 \mathrm{~h}, 3 \mathrm{~h}$ and $24 \mathrm{~h}$ time of reaction, respectively. Figure 4 shows the effect of COD removal. The percentage of COD removal increased when the dose of manganese (II) was raised.

The maximum percentage of COD removal was about $65 \%$ (for $500 \mathrm{mg} / \mathrm{L}$ manganese (II) dose). As the manganese (II) dose increased to $600 \mathrm{mg} / \mathrm{L}$, the percentage of COD removal dropped significantly. This observation is in line with the study of Abdel-Aal et al. (2015) and Song et al. (2001).

The impact of initial $\mathrm{pH}$ between 8.5 and 9.5, for manganese (II) dose of $400,500 \mathrm{mg} / \mathrm{L}$, on sulphide removal from wastewater was investigated. 


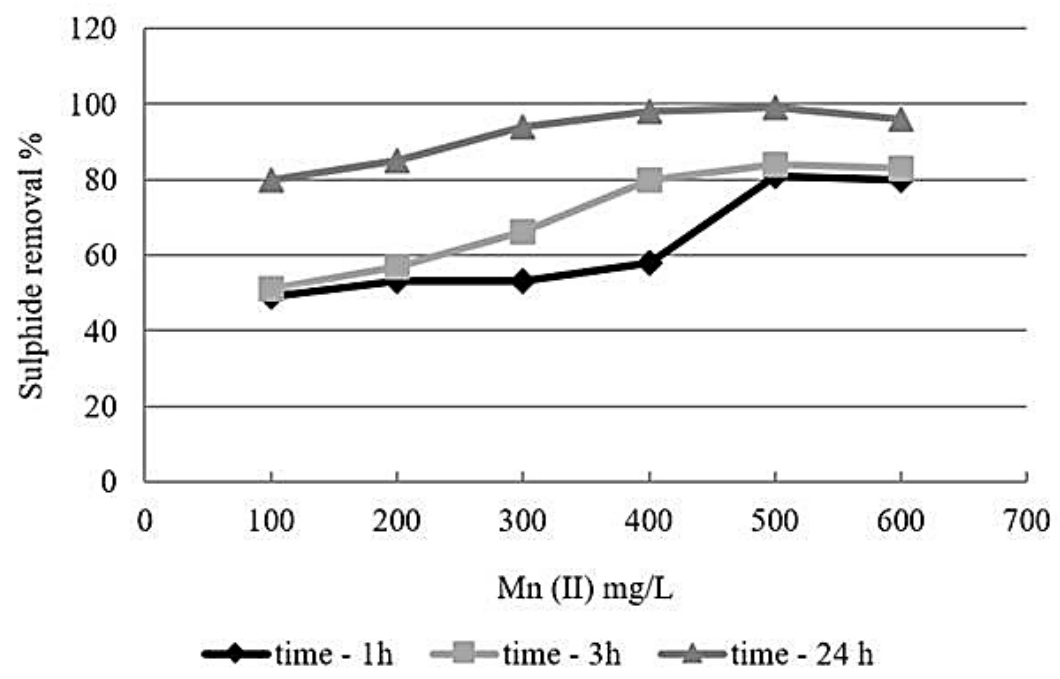

Figure 3. Effect of manganese (II) dose on sulphide removal

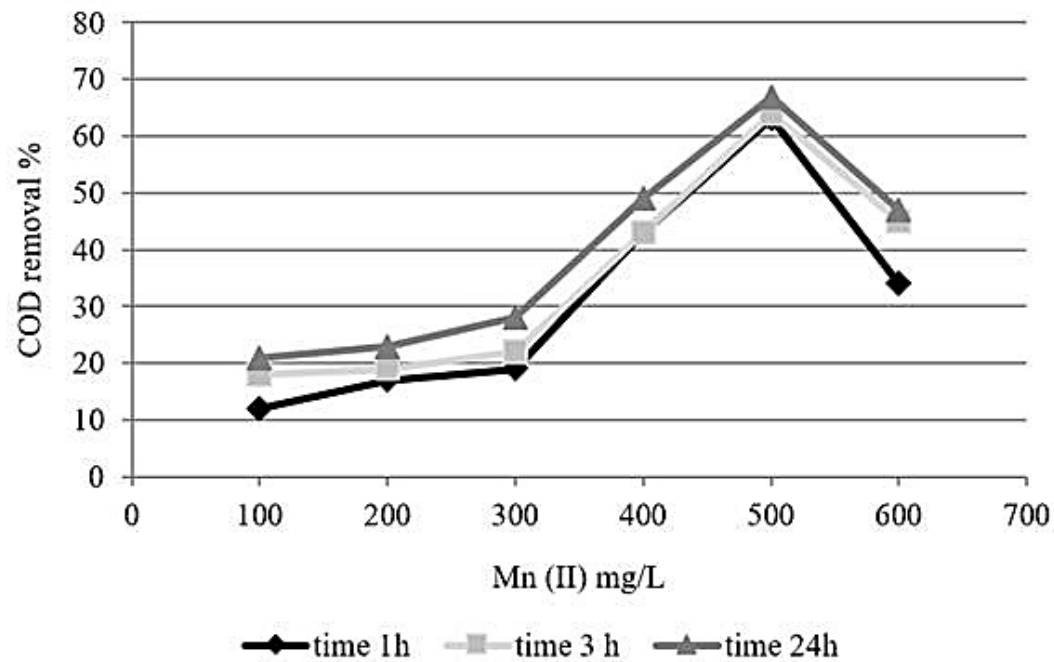

Figure 4. Effect of manganese (II) dose on COD removal

The initial $\mathrm{pH}$ values of wastewater were adjusted with $0.1 \mathrm{M} \mathrm{Ca}(\mathrm{OH})_{2}$ or $0.1 \mathrm{M} \mathrm{HCl}$, as required at the beginning of the experiment.

The initial $\mathrm{pH}$ values of the wastewater had a great impact on the efficiency of sulphide removal at a manganese (II) concentration of $400 \mathrm{mg} / \mathrm{L}$. Low $\mathrm{pH}$ (8.5) enables to achieve more effective sulphides removal than high $\mathrm{pH}$ (9.5). Higher amounts of sulphide are removed when the $\mathrm{pH}$ decreases: $53-66 \%$ of sulphide was removed at $\mathrm{pH} 8.5$, while $40-44 \%$ at $\mathrm{pH} 9.5$. For manganese (II) addition at a concentration of $500 \mathrm{mg} / \mathrm{l}$ the solution $\mathrm{pH}$ is not a significant factor in sulphide removal. The percentage of sulphide removal was $83 \%$ on average for both $\mathrm{pH} 8.5$ and 9.5 .

The impact of $\mathrm{pH}$ on the percentage of sulphides removal from tannery wastewater by means of manganese (II) is shown in Figure 5.
The presented results indicate that the reaction time has an effect on sulphides and COD removal. The rate of sulphides removal and COD reduction with respect to time are shown in Figure 6 and Figure 7, respectively

Small changes were observed in the sulphide elimination rates between $1 \mathrm{~h}$ and $3 \mathrm{~h}$, while significant ones, in the range of $30 \%$ to $40 \%$, were noted between $3 \mathrm{~h}$ and $24 \mathrm{~h}$.

The results of the oxidation after $3 \mathrm{~h}$ were insufficient to achieve adequate removal efficiency for sulphides and COD. The values exceeded the limits which did not allow a direct discharge of wastewater to the receiver or sewage treatment plants. Thus, the recommended reaction time for obtaining high sulphide and COD removal was $24 \mathrm{~h}$. Similar observation on COD removal was made by Chowdhury et al. (2013). 


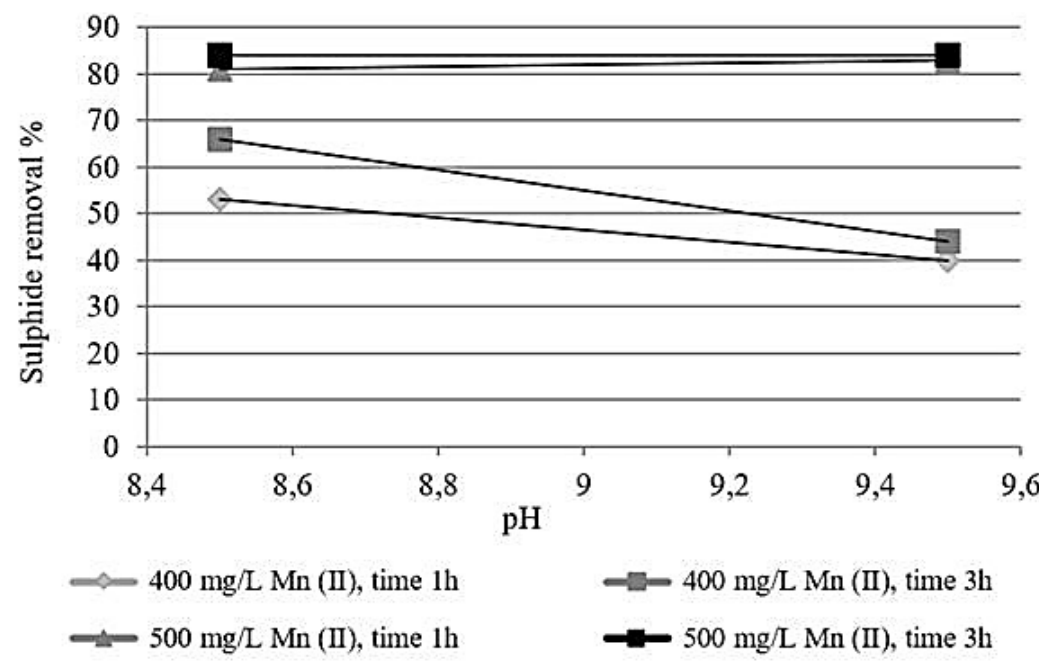

Figure 5. Effect of $\mathrm{pH}$ on percentage of sulphides removal

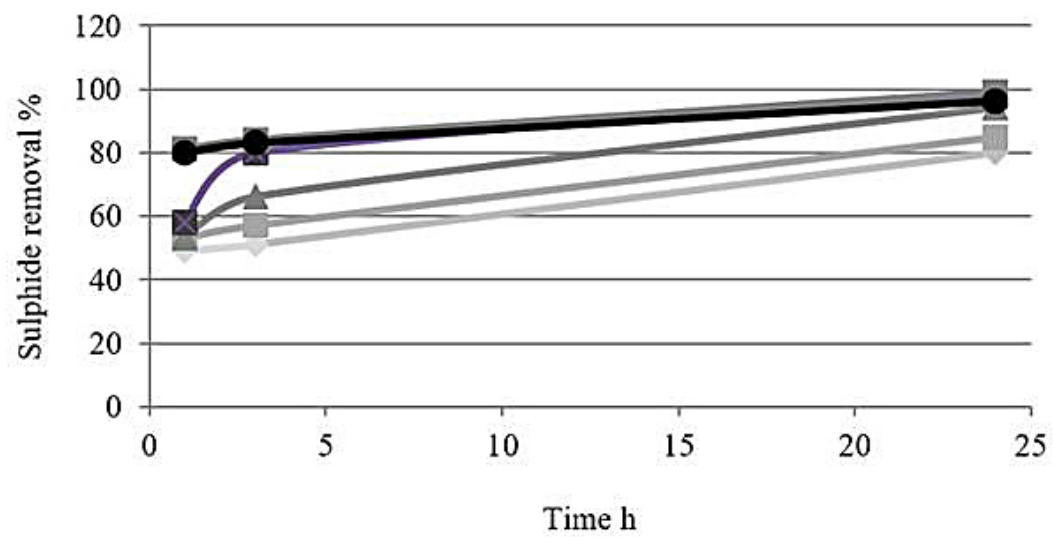

$100 \mathrm{mg} / \mathrm{L} \mathrm{Mn}$ (II) $=-200 \mathrm{mg} / \mathrm{L} \mathrm{Mn}$ (II) $-300 \mathrm{mg} / \mathrm{L} \mathrm{Mn}$ (II)

$400 \mathrm{mg} / \mathrm{L} \mathrm{Mn} \mathrm{(II)}=500 \mathrm{mg} / \mathrm{L} \mathrm{Mn}$ (II) $-600 \mathrm{mg} / \mathrm{L} \mathrm{Mn} \mathrm{(II)}$

Figure 6. Effect of time on removal percentage of sulphides

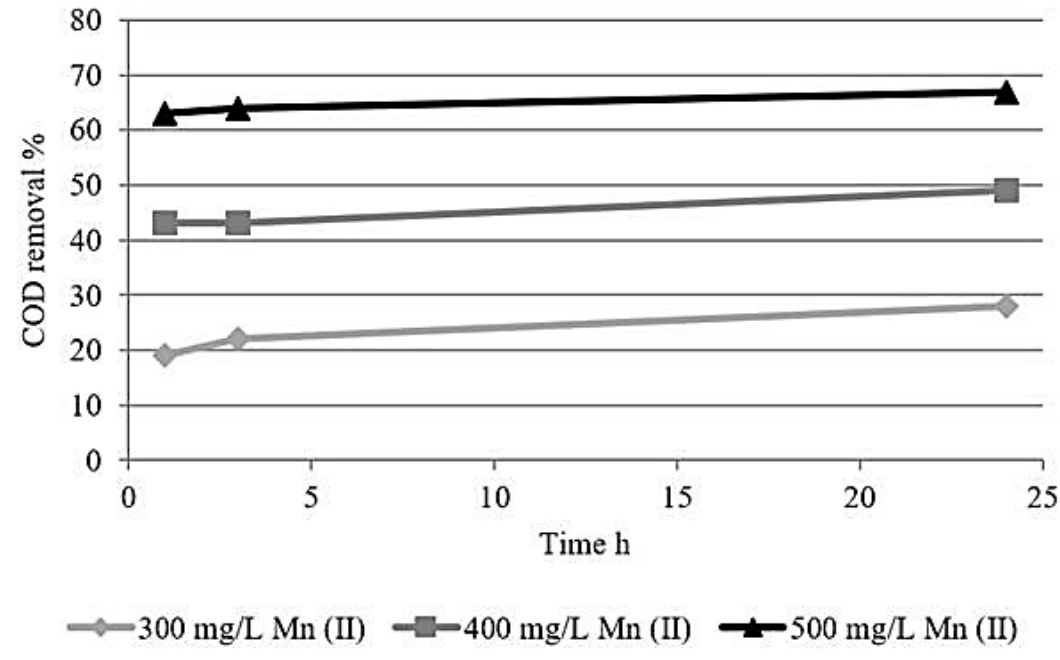

Figure 7. Effect of time on removal percentage of COD 
COD removal remains constant as the reaction time of tanning wastewater treatment increases. The results obtained for duration of treatment between $3 \mathrm{~h}$ and $24 \mathrm{~h}$ did not vary considerably - the increase was below $10 \%$.

The catalytic oxidation with manganese (II) to a great extent contributes to the removal of sulphides from tannery wastewater. However, the efficiency of the process depends on time and dose of manganese (II). Using high doses of manganese (II) and a 24-hour-long process is costly and not economically feasible.

Despite the obtained results, this process cannot be used to remove the sulphides to the level required for the discharge of wastewater directly to the receiver or sewage treatment plants. This process can be used as a preliminary process for tannery wastewater treatment. Since sulphides are a high nuisance parameter of the wastewater tested, even their partial removal is advisable.

\section{CONCLUSIONS}

The results of the discussed studies indicate that none of the analysed techniques allows for the complete elimination of pollutants from the separated sewage streams. The highest removal efficiency of organic compounds does not exceed $80 \%$ and is characterized by the Fenton reagent process.

The catalytic oxidation process in the presence of manganese (II) greatly contributes to the removal of sulphides from tannery wastewater up to $99 \%$. However, the effectiveness of the process depends on the duration and manganese dose. Using high doses of manganese at the level of 0.5 $\mathrm{g} / \mathrm{dm}^{3}$ and more and conducting the process for 24 hours is costly and not economically feasible. Despite the obtained results, the process cannot be considered as an option to remove sulphides to the level required for the discharge of waste water directly to the receiver or wastewater treatment plant. This process can be used as a process supporting tannery wastewater treatment, and due to the fact that sulphides are a high nuisance parameter of the wastewater tested, their even partial removal is advisable.

The analysis of the study results for various wastewater streams allowed us to formulate the following conclusions:

1. The highest efficiency of tannery wastewater treatment in Fenton process was obtained for
$\mathrm{Fe}^{2+} / \mathrm{H}_{2} \mathrm{O}_{2}$ reactant dosages of $0.56 / 4.08 \mathrm{~g} / \mathrm{dm}^{3}$ corresponding to $\mathrm{Fe} / \mathrm{H}_{2} \mathrm{O}_{2}$ ratio of 1:7. The efficiency of this process, expressed by COD reduction, was $80 \%$.

2. Increasing the dose of $\mathrm{Fe}^{2+}$ from $0.45 \mathrm{~g}$ to 0.56 $\mathrm{g} / \mathrm{dm}^{3}$ and $\mathrm{H}_{2} \mathrm{O}_{2}$ respectively to achieve a 1:5, 1:6 and $1: 7 \mathrm{Fe} / \mathrm{H}_{2} \mathrm{O}_{2}$ ratio, increased COD removal by an average of $4 \%$.

3 . Using the process of catalytic oxidation with $0.1 \mathrm{~g}$ to $0.6 \mathrm{~g} / \mathrm{dm}^{3}$ of manganese and a reaction time of $1,3,24 \mathrm{~h}$, the sulphides were removed in the range of 50 to $99 \%$ and organic compounds in 12 to $65 \%$.

4. A manganese dose of $0.4 \mathrm{~g} / \mathrm{dm}^{3}$ for wastewater treatment in the catalytic oxidation process is optimum, as the simultaneous removal of sulphides (80-99\%) and organic compounds expressed as COD (40-50\%) occurs.

5. By using manganese in an amount of $0.1 \mathrm{~g} /$ $\mathrm{dm}^{3}, 50 \%$ of sulphide removal can be achieved within 1 hour.

6 . The process of tannery wastewater treatment by use of manganese (II) is useful for the pretreatment of tannery wastewater in order to reduce the content of sulphide.

\section{REFERENCES}

1. Abdel-Aal E.A., Farghaly F. E., Abdel- Wahed R.T., El-Shahat M.F. 2015. Treatment of Industrial Wastewater Using Advanced Oxidation Processes. International Journal of Scientific in Agricultural Sciences, 2(Proceedings), 68-78

2. APHA.2005. Standarts Methods for the Examination of Water and Wastewater.21 ed. America Public Health Associoaton. Washington

3. Ayoub G.M., Hamzeh A., Semerjian. 2011. Post treatment of tannery wastewater using lime/bittern coagulation and activated carbon adsorption. Desalination, 273, 359-365.

4. BAT. (2013). Best Available Techniques Reference Document for the Tanning of Hides and Skin. Available at: http://life-shoebat.eu/en/search-tools/ tannery-bats/item/tannery-45-en.

5. Barbusiński K. (2009). Fenton reaction- controversy concerning the chemistry. Ecological Chemistry and Engineering S, 16,3,347-358.

6. Cesaro A. Naddeo V., Belgiorno V. 2013. Wastewater treatment by combination of advanced oxidation processes and conventional biological systems. Bioremediation and Biodegradation 4, 18, 1-8.

7. Chowdhury M., Mostafa M.G., Tapan Kumar Biswas, Ananda Kumar Saha. 2013. Treatment of leather in- 
dustrial effluents by filtration and coagulation processes. Water Resources and Industry, 3, 11-22.

8. Cooman K., Gajardo M., Nieto J., Bornhardt C., Vidal G. 2003. Tannery Wastewater Characterization and Toxicity Effects on Daphnia spp. Environmental Toxicology, 18, 45-51.

9. Durai G., Rajasimman M. 2011. Biological Treatment of Tannery Wastewater - A Review. Journal of Environmental Science and Technology,4, 1-17.

10. Kociołek - Balawejder E, Wilk Ł. (2012a). Sulfides in aqueous enviroment. Part 2. Preventing the emission and removal. Przemysł chemiczny.91/12, $2345-2350$

11. Kociołek - Balawejder E, Wilk Ł. (2012b). Sulfides in aqueous enviroment. Part 1. Preventing theformation. Przemysł chemiczny. 91/12, 2339-2344

12. Kotulska M., Ozonek J. 2006. Treatment of tanning sewage on biological submerged foundation. Gaz, woda i technika sanitarna, 12, 29-33.

13. Kowalik A., Kluziński W., Gierycz P. 2009. Microfiltration and ultrafiltration of tannery wastewaters. Problemy eksploatacji, 1, 135-144.

14. Lofrano $G$, Meriç $S$, Inglese $M$, Nikolaou $A D$, Belgiorno V. (2010) Fenton oxidation treatment of tannery wastewater and tanning agents: synthetic tannin and nonylphenol ethoxylate based degreasing agent. Desalination Water Treat.23,1.

15. Lofrano G, Meriç S, Zengin GE, Orhon D.2013. Chemical and biological treatment technologies for leather tannery chemicals and wastewater: A review. Science of the Total Environment, 461-462, 265.

16. Mandal T., Dasgupta D., Mandal S., Datta S. 2010. Treatment of leather industry wastewater by aerobic biological and Fenton oxidation process. Journal of Hazardous Materials, 180, 204-211.

17. Mendrycka M., Stawarz M. 2012. Possibilities of applications of biocomponent for biological processes of tanning sewage by activated sludge-aided method. Inżynieria Ekologiczna, 28, 43-56.

18. Naumczyk J., Rusiniak M. 2005. Physicochemical and chemical purification of tannery wastewaters. Polish Journal of Environmental Studies 14 (6), 789-797.

19. Neyens E., Baeyens J., 2003. A review of classic Fenton's peroxidation as an advanced oxidation technique. Journal of Hazardous Materials. 98 (1-3), 33-50.

20. Przywara L. 2017. Application of Fenton's process for treatment of tannery wastewater Inżynieria Ekologiczna, 18, 117-122

21. Rameshraja D., Suresh S. 2011 .Treatment of Tannery Wastewater by Various Oxidation and Combined Processes Review. J. Environ. Res. 5(2), 349360.

22. Schrank S.G., Jose H.J., Moreira R.F.P.M., Schroder H.F.2004. Comparison of different Advanced Oxidation Process to reduce toxicity and mineralization of tannery wastewater. Water Science Technology, 50 (5), 329-334.

23. Schrank S.G., Jose H.J., Moreira R.F.P.M., Schroder H.F.2005. Applicability of Fenton and H2O2/ UV reactions in treatment of tannery wastewater. Chemosphere 60, 644-655

24. Song Z., Williams C.J, Edyvean R.G.J. 2001. Coagulation and anaerobic digestion of tannery wastewater. Trans IChemE. 79, 23-28.

25. Song Z., Williams C.J, Edyvean R.G.J. 2004.Treatment of tannery wastewater by chemical coagulation. Desalination 164, 249-259

26. Xing M.Y., Can D., Godefraid B., Yang J. 2006. Treatment of pharmaceutical wastewater containing recalcitrant compounds in a Fenton-coagulation process. Journal of Environmental Since, 18(3), 459-463. 